\title{
EL RADICALISMO ALICANTINO EN LA II REPUBLICA
}

Octavio Ruiz Manjon-Cabeza

Universidad de Granada

\author{
DIFICULTADES EN LA ARTICULACION POLITICA \\ DEL REPUBLICANISMO ESPAÑOL \\ DURANTE LA SEGUNDA REPUBLICA. \\ EL CASO DEL RADICALISMO ALICANTINO
}

Resulta innecesario detenerse excesivamente en explicar que la guerra civil española no significó, precisamente, una circunstancia favorable para la supervivencia de los archivos de los partidos políticos que existieron antes de 1936. Si los protagonistas más significados tuvieron dificultades en poner a salvo sus archivos particulares, bien puede imaginarse lo que ocurrió con la masa de documentación burocrática que dichos partidos generaron.

Sin embargo, fueron precisamente las circunstancias de la guerra civil las que permitieron reunir un gran fondo documental cuyos frutos de investigación no han hecho sino empezar a producirse. La sección de la guerra civil del Archivo Histórico Nacional, a la que me estoy refiriendo, reúne en Salamanca un fondo documental en el que aún descansan miles de documentos que podrán arrojar una gran luz sobre nuestra historia más reciente ${ }^{1}$.

1 María Teresa Díez de los Ríos, archivera jefe de dicha sección, presentó una ponencia, en la que se describían estos fondos, al Coloquio Internacional sobre la Segunda República Española, que se celebró en Tarragona en abril de 1981. También se puede consultar el artículo introductorio y descriptivo de J. A. Ferrer Benimelli, "Archivo de la Guerra Civil de Salamanca", en Historia 16. núm. 69 (I, 1982), págs. 109-†15. 
La tarea de recogida de documentos se hizo al paso de los acontecimientos bélicos y, por eso, no es extraño que Alicante, la última ciudad en caer en manos nacionalistas, haya dado lugar a una importante masa documental - de ciento cincuenta y tres carpetas - cuyos primitivos catálogos ${ }^{2}$ permiten alentar la esperanza de que, con el tiempo, pueda ser una provincia en la que se tenga una imagen muy precisa de las fuerzas sociales y políticas que en ella actuaron. Junto a la documentación relativa a José Alonso Mallol, que fue gobernador de Sevilla y director general de Seguridad, al diputado Jerónimo Gomáriz, a José Estruch, o a José Irles Negro, hay también documentación de partidos políticos, como pueden ser el comunista, el socialista, el de Izquierda Republicana o el Radical Socialista. También hay documentación referente a sindicatos obreros, patronales, organos de prensa (Liberación y Nuestra Bandera) y organizaciones asistenciales.

Por otra parte, hemos podido consultar la documentación relativa al diputado César Oarrichena Genaro, que se halla contenida en las carpetas 519 a 522 y 568 a 571 del índice referente a Madrid. En dichas carpetas se contiene correspondencia del político alicantino, así como una muy rica documentación referente al Partido Radical de la provincia de Alicante, que sería susceptible de ser elaborada de la forma que ya lo han sido otras organizaciones políticas provinciales ${ }^{3}$. Para ello contamos, entre esta documentación alicantina, con listas de afiliados, actas de diversos comités, circulares y panfletos que parecen esperar la visita de algún investigador que sepa sacar parti-

2 El autor trabajó en ese archivo cuando sólo se disponia de unos catálogos muy elementales, que apenas ayudaban al investigador. Aunque sabe que está en fase muy adelantada, si no completa, una nueva tarea de catalogación, basa sus actuales indicaciones en la exploración directa que realizó a comienzos de la década de los setenta.

3 Cfr. Ruiz Manjón-Cabeza, Octavio, "El Partido Republicano Radical de Madrid durante la Segunda República Española», en Revista de la Universidad de Madrid, XXII, 87 (VII-IX, 1973), págs. 233-256; y RuEdA HERnÁnz, Germán, «El Partido Agrario Español (1934-1936). (Análisis sociológico de la sección valenciana y estudio comparativo con la agrupación madrileña del Partido Republicano Radical)", en Revista de Estudios Políticos, núms. 206-207 (1976), págs. 303-323. 
do de tan interesante material. Tan sólo cabe desear aquí que estas líneas sirvan de desencadenante de una empresa que se presume tan fructífera.

Por otra parte, nos limitaremos a utilizar algunos documentos extraídos de la correspondencia de Oarrichena, que nos revelan mucho de la vida alicantina de aquellos años y, más concretamente, de las dificultades de organización del Partido Radical.

En cuanto al receptor de buena parte de esta correspondencia, cabe decir que César Oarrichena Genaro fue un destacado radical alicantino y que obtuvo la representación parlamentaria alicantina en las elecciones de junio de 1931 y en las de noviembre de 1933. Hay noticias de su militancia en las filas republicanas desde bastantes años antes, pues aparece como representante alicantino en el congreso de la Democracia Republicana que se celebró en Madrid, en noviembre de 19204. Antonio Sánchez Fuster, secretario personal de Lerroux, le escribe el 5 de agosto de $1930^{5}$ y estampa, junto a la firma, los tres puntos que son indicio de la común pertenencia a la masonería.

\section{LA VIDA POLITICA ALICANTINA}

\section{EN LOS INICIOS DE LA SEGUNDA REPUBLICA}

Las elecciones municipales de abril de 1931 habian proporcionado en Alicante, al igual que en la casi totalidad de las capitales españolas, un triunfo republicano que, a la vez, constituia un primer indicador de la correlación de fuerzas entre los republicanos y los socialistas alicantinos.

4 Libro de oro del Partido Republicano Radical, Madrid, Sucesores de Rivadeneyra, S. d. (1935), pág. 112.

5 Archivo Histórico Nacional, Sección de la Guerra Civil, Salamanca, índice de Madrid, carpeta 569, legajo 4768. En adelante se citaría AHN-GC, Madrid, C 569, L 4768. 
El resultado fue como sigue ${ }^{6}$ :

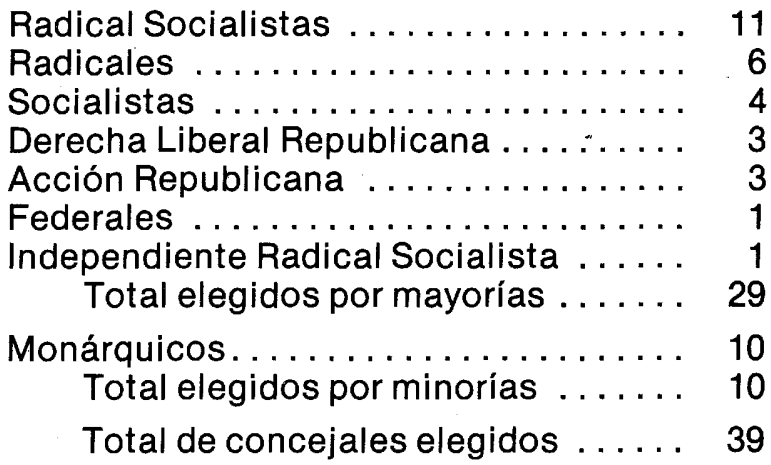

El resultado apuntaba un cierto predominio de los elementos radical-socialistas, que se confirmaría en los años siguientes, en competencia con unos socialistas que cabe considerar subrepresentados en este momento. Los radicales se perfilaban como fuerza canalizadora de los intereses republicano-burgueses, mientras que los endebles resultados de otras fuerzas politicas eran justa correspondencia de la debilidad de su implantación en aquella provincia.

Los meses que transcurrieron hasta las primeras elecciones generales, de 28 de junio de 1931, modificaron ya este panorama pues, para comenzar, se rompió la conjunción republicano-socialista que había obtenido el triunfo de abril 7 .

La candidatura que se presentó para los ocho puestos de las mayorías estaba compuesta por cuatro radicales socialistas, tres socialistas y un republicano independiente, que más tarde se integraría en el partido de Azaña.

6 Ayuntamiento de Alicante, Memoria de la Secretaría Municipal. 16 de abril de 1931-31 diciembre de 1932, Alicante, Modernas Gráficas Gutenberg, 1933, páginas 14-16.

7 Chapaprieta, Joaquín, La paz fue posible, Barcelona, 1971, pág. 156. 
Para llegar a esta oferta electoral, sin embargo, hubo que librar una batalla de influencias en la que se clarificó mucho el peso real de los partidos dentro de la provincia.

El que parecia más fuerte, el radical socialista, no lo era tanto pues, en una población tan importante como Aspe, aún estaban implantando el partido en vísperas de las elecciones, ya que hemos podido encontrar ${ }^{8}$ hojas de propaganda en las que se anunciaba la organización del partido en esa población.

Las diferencias entre republicanos, que Ilevarían a la reducida oferta electoral antes aludida, motivó incluso que aparecieran candidaturas integradoras, basadas en nombres de prestigio, en las que parecían anteponerse los intereses alicantinos a los puramente partidistas. Los alicantinos pudieron leer, en una hoja de propaganda ${ }^{9}$ que se repartió por aquellos días, el siguiente texto:

A la opinión:

Creemos que a las Cortes Constituyentes, precisamente por la alta misión que les está confiada, deben ir aquellas personas que por su prestigio y clara mentalidad estén perfectamente capacitadas para intervenir de una manera eficaz y fructífera en los debates que se han de suscitar.

Toda claudicación en este sentido, atendiendo a cualquier otra razón, nos parece suicida. Hemos de contribuir, pues, por todos los medios, a que vayan a las Cortes tales personas, que el nivel mental de aquéllas ofrezca un aspecto verdaderamente europeo. Lo demás, sólo son mezquindades, politiquerías y ganas de llegar; unas ganas de llegar por demás apresuradas y muy viejo régimen.

Por todo lo expuesto, nos permitimos recomendar a la opinión sana - que nada tiene que ver con todas estas cosas - la siguiente candidatu$\mathrm{ra}$, integrada por personas de relevante prestigio en uno u otro orden.

Votar la misma es afianzar, en la parte que a Alicante corresponde, la elevación de los debates, con miras a una estructuración social verdaderamente nueva; la que necesita España, que, por lo mismo que ha perdido mucho tiempo durante el régimen estéril, necesita ganarlo más deprisa y con mayor dignidad de lo que algunos estiman.

8 AHN-GC, Madrid, C 570, L 4769.

9 Ibidem. 


\author{
Rodolfo Llopis \\ Carlos Esplá \\ Angel Pascual y Devesa \\ Rafael Altamira \\ José Martínez Ruiz "Azorín» \\ Julio María López \\ Juan Botella Asensi \\ Romualdo Rodríguez de Vera \\ José Sanchís Banús \\ Augusto Villalonga \\ Germán Bernácer.
}

La sugerencia carecía de viabilidad e interés en un momento en el que España emprendía decididos pasos de modernización política a través de la actuación de los partidos, y sólo sirve para confirmar el prestigio local que disfrutaban personalidades como la del gran escritor Azorín, el economista Bernácer o el historiador Altamira. Azorín, en cualquier caso, se presentaría bajo la etiqueta de republicano federal y, pese a sus intentos de justificar su colaboración con el anterior régimen ${ }^{10}$, el resultado electoral sería desastroso y confirmaba la idea de que, en las nuevas circunstancias políticas españolas, un prestigio literario no era suficiente para acceder al Congreso de los Diputados.

Los verdaderamente perjudicados por la coalición de republicanos de izquierda y socialistas fueron el partido de Derecha Liberal Republicana y el Partido Radical, que competían por el sector más conservador del electorado.

El organizador, a escala nacional, de la campaña de los primeros era el alicantino Joaquín Chapaprieta y, aunque reconocía que la Derecha Liberal Republicana «no tenía organización estimable en la provincia» ${ }^{11}$, creía tener fuerza suficiente para ganar los tres puestos reservados a la minoría. En la imprenta del periódico El Día se imprimió una hoja propagandística ${ }^{12}$ que pedía el voto "en bien de la paz social" y condenaba el posible abstencionismo.

10 Valverde, J. M., Azorín, Barcelona, 1971, pág. 367.

11 Chapaprieta, Joaquín, op. cit., pág. 156.

12 AHN-GC, Madrid, C 570, L 4769. 
A la opinión de la provincia de Alicante

Ciudadanos:

El partido de la derecha republicana se dispone a luchar en las próxi. mas elecciones de diputados a Cortes Constituyentes, y con la plena conciencia de la alta misión que ha de cumplir en la política española, se dirige a la opinión sana de la provincia de Alicante para que con el entusiasmo sereno que la caracteriza y que pone el ideal en las voluntades ciudadanas, acuda a las urnas electorales y deposite su voto a favor de nuestra candidatura en bien de la paz social, de la República y de España.

Horas son éstas de profunda lucha; de combate rudo. Deber de ciudadanía, e inexcusable deber de españolismo, es defender con la emoción histórica del momento y con la viril firmeza del derecho, aquellos altos ideales de paz, de orden, de libertad bien entendida, y de justicia valientemente aplicada, que, sobre consolidar la República, han de pregonar el nombre de España con el respeto que impone la categoría de las grandes democracias.

Os llama también a estos Comicios el hecho vivo y candente de la revolución social en marcha, no para contenerla ni desvirtuarla, porque las revoluciones son santas cuando van precedidas de una bandera de justicia, sino para encauzarla, para que no se malogre, para que los nerviosismos de los unos y el espíritu de secta de los otros no la hagan precipitarse y caer en las revueltas del atropello y la anarquía. Pensad que, instaurada la República en España bajo el impulso creador de las masas electorales, el poder emana exclusivamente del pueblo, y de su voluntad soberana han de surgir las normas reguladoras de la vida del país. En su virtud, toda pasividad o abstención en la próxima contienda electoral equivaldrá a un suicidio y a un crimen de lesa patria. Los que quieran defender sus ideas han de hacerlo en las urnas con las armas del voto.

Y para eso, para que las aguas revolucionarias no se desborden y se conviertan en río revuelto, para que la revolución sea fecunda y redentora, precisa que todos aquellos elementos que son conservadores ante la anarquía, pero que son también revolucionarios ante la reacción, acudan a votar nuestra candidatura para la afirmación del orden social, como garantía del derecho, y de la verdadera libertad, que es siempre una consecuencia del orden. Los momentos son graves porque son decisivos, de ellos depende el porvenir de nuestra querida patria. En las próximas Constituyentes se van a plantear hondos y complejísimos problemas, alrededor de los cuales ha de girar la vida nacional; y en estos momentos solemnes en que la voz de la conciencia hace enmudecer a la voz de la pasión, gritemos todos:

¡Viva España! ¡Viva la República!

El Comité

Los radicales, por su parte, intentaron vanamente mantener la coalición triunfante en el mes de abril, pero, al verse desplazados, reaccionaron violentamente y calificaron de traidores a los que les excluían de la coalición presumiblemente triunfante. Su 
propaganda ${ }^{13}$, que se imprimía en el Diario de Alicante, desarroIló ampliamente estos conceptos:

\section{ANTE LA LUCHA ELECTORAL} A LOS RADICALES DE LA PROVICIA

Ha sido el partido radical en todo momento, el más fervoroso y entusiasta mantenedor de la coalición de partidos republicanos. Hemos creido siempre, y los hechos históricos han venido a darnos la razón, que para derrumbar la monarquia borbónica precisaba la unión de todas aquellas fuerzas políticas en cuyos programas se sentaba como postulado primordial la implantación de la República. Conquistada la primera frontera al enemigo en la gloriosa fecha del 12 de abril y adueñados del campo de batalla dos días después, seguimos manteniéndonos firmes en nuestro criterio de que la coalición republicano-socialista lograda en el llamado pacto de San Sebastián, era más precisa que nunca para la consolidación definitiva de la segunda República española. En este afán nuestro, inspirados tan sólo en el amor que sentimos por el nuevo régimen, pusimos todos nuestros empeños y condensamos todos nuestros anhelos. Al convocarse las Cortes Constituyentes por el Gobierno Provisional de la República, mantuvimos una vez más el criterio de que la coalición republicano-socialista que luchó en las elecciones municipales del mes de abril, debía subsistir con más cohesión, con una mayor compenetración, hasta ver consolidada y estructurada en su ley fundamental, la República naciente.

Sin embargo, todo nuestro generoso empeño, todo nuestro gesto de abnegación y todo nuestro afán de seguir sacrificando para el bien del régimen la significación destacada de nuestro partido político - forjado, al fin y al cabo, en el crisol del desprendimiento como lo prueba nuestra historia- ha tropezado en estos difíciles momentos con egoismos mezquinos y personalismos al estilo del viejo régimen, por parte de quienes debieron poner más cuidado en la defensa de la República que en el interés y en la ambición de sectores políticos siempre respetables, pero siempre supeditados también a la prosperidad y engrandecimiento del nuevo Estado Español. Nuestro anhelo generoso de llamar hermanos a todos los que luchamos en diciembre, cuando España se estremecia ante el aguafuerte de Jaca, y en abril, cuando nuestra nación dió al mundo entero una lección de civismo y ciudadania, ha chocado con los eternos Judas de la política, que faltando a los pactos acordados por los distintos partidos, han pretendido vender y destruir al glorioso partido radical, que nacido y moldeado en la lucha, y para la lucha, hoy, con la conciencia de su responsabilidad y su grandeza creados por la situación que ostenta en la política española, fiel como siempre a sus propósitos y su programa se apresta una vez más para la batalla, en coalición con la única fuerza republicana que no levantó aparte bandera política y que todavia puede merecer el dictado de hermana, ya que como hermana luchó con nosotros en las calles y en las urnas contra la monarquia, y como hermana ahora, aunque con distinto matiz político al nuestro, viene a ser un freno para las impaciencias y los extremismos.

Ibidem. 
Enemigos de la guerra, vamos a ella en las próximas elecciones porque la guerra se nos ha declarado por quienes traicionaron un pacto. Seguros estamos de salir victoriosos en la contienda porque nuestra significación y nuestro programa no son susceptibles de adulteraciones incompatibles con quien, como el Partido Radical, no claudicó jamás. Nosotros respondemos al reto que se nos lanza, con la batalla generosa y leal de las urnas. Nuestra historia abona el republicanismo que sentimos y pregonamos. Vamos unidos a quienes nos dieron la mano el 12 de abril y hoy siguen siendo nuestros hermanos, aunque dentro de la gran familia republicana, tenga cada hermano su color, su talla y su historia. Pero hoy los hermanos se unen para la defensa de su hogar, que es la República.

RADICALES TODOS DE NUESTRA PROVINCIA:

El partido que acaudilla el ilustre hombre de Estado, don Alejandro Lerroux, confía una vez más en vosotros. Sabe que tiene toda vuestra confianza y que vuestra fé y vuestras esperanzas republicanas están cristalizadas en los que luchamos por su engrandecimiento. Con esa fé y esas esperanzas vuestras, hermanadas con la disciplina de que siempre hicimos gala, habeis de votar, integra, la candidatura de nuestra coalición.

\section{LA JUNTA PROVINCIAL}

Derecha Liberal Republicana y Partido Radical se vieron abocados, por lo tanto, a una coalición paritaria de resultado incierto y ante la que Chapaprieta parece que abrigó algunos recelos.

La provincia alicantina asistió, por demás, a una lucha electoral en la que, frente a la ausencia de los candidatos declaradamente de derechas, republicanos y socialistas, se disputaban los escaños disponibles con el máximo de dispersión en las candidaturas. Los radicales socialistas, radicales y republicanos de derecha aportaban cinco candidatos, mientras que socialistas y federales concurrían con tres, y Acción Republicana aportaba dos. Por otra parte, había tres candidatos que se presentaban como republicanos independientes ${ }^{14}$. La dispersión no podía ser mayor y las posibilidades de combinación electoral casi infinitas ${ }^{15}$.

14 TuselL, J., Las constituyentes de 1931: unas elecciones de transición, Madrid, 1982, pág. 54.

15 Según el decreto electoral de 8 de mayo de 1931, cada votante podia elegir libremente un cierto número de candidatos. En el caso de Alicante, hasta ocho de los once puestos disponibles. 
Los resultados electorales ${ }^{16}$ vinieron a confirmar esas posibilidades de dispersión, especialmente en los puestos correspondientes a la minoría.

Escaños a elegir: 11.

Diputados elegidos: 11.

Electores: 159.932.

Votantes: 111.186.

Participación: 69,52\%.

Carlos Esplá (RI) . . . . . . . . . . . . . . 71.841 E

Rodolfo Llopis (PSOE) . . . . . . . . . . . . . . 73.841 E

Romualdo Rodríguez Vera (PSOE) . . . . . . 63.453 E

Manuel González Ramos (PSOE) . . . . . . . . 62.403 E

Antonio Pérez Torreblanca (RDTS) . . . . . 6 67.297 E

Juan Botella Asensi (RD-S) . . . . . . . . . . . . . $64.899 \mathrm{E}$

Julio María López-Orozco (RD-S) . . . . . . . 67.013 E

Miguel de Cámara (RD) . . . . . . . . . . . . 35.412 E

César Oarrichena Genaro (RD) . . . . . . . . 33.054 E

César Puig (RD) .............. 33.617 E

Jerónimo Gomáriz (RD-S) . . . . . . . . . . 33.308 E

Joaquín Chapaprieta (DLR) $\ldots \ldots \ldots \ldots \ldots .32 .914$

Romualdo Catalá (DLR) . . . . . . . . . . . . 26.283

Manuel Palomares (RD) . . . . . . . . . . . 27.495

José Cañizares (DLR) . . . . . . . . . . . . $\quad 26.441$

Gregorio Ridaura (DLR) . . . . . . . . . . . . $\quad 25.197$

Pedro Beltrán (DLR) . . . . . . . . . . . . . . . . 23.797

Angel Pascual y Devesa (AR) . . . . . . . . . . 18.374

Mateo Hernández Barroso (AR) . . . . . . . . 14.444

José Pérez García (FED) . . . . . . . . . . . . . . 10.513

Francisco Javier Morata (RD) . . . . . . . . . . 10.414

José Escudero (RD-S) . . . . . . . . . . . . $\quad 6.656$

José Martínez Ruiz (FED) . . . . . . . . . . 2.923

Germán Bernácer (RI) . . . . . . . . . . . . . $\quad 2.751$

Francisco Figueras (FED) . . . . . . . . . . . . . 1.304

Oscar Esplá (RI) . . . . . . . . . . . . . . . . 539

Otros ..................... 4.560

En blanco ................... 303

16 TuselL, J., op. cit., pág. 162. 
Los resultados confirmaban el predominio de socialistas y radical-socialistas ${ }^{17}$ y Chapaprieta, por su parte, creía ver confirmados los temores que había engendrado cuando aceptó la colaboración con los seguidores de Lerroux. "Los radicales se aprovecharon de nuestro voto y deslealmente dejaron de incluirnos a los candidatos de la derecha republicana en sus candidaturas» ${ }^{18}$. De todas maneras, Joaquín Chapaprieta habría salido elegido si la Comisión de Actas del Congreso no hubiera mantenido un criterio, que Tusell califica de "un tanto laxo» ${ }^{19}$, para respaldar el dictamen de la Junta Provincial.

El Partido Radical, en cualquier caso, quedó consolidado como una fuerza republicana bien asentada en el ámbito alicantino a través de su nutrida representación parlamentaria, pero sería engañoso creer que la organización provincial alcanzaría pronto una solidez acorde con los ventajosos resultados conseguidos en las elecciones.

A finales de septiembre de ese mismo año, César Oarrichena recibía una carta ${ }^{20}$, con membrete de la Secretaría del Partido en Alicante, y en la que parecen leerse las firmas de José María Ruiz Pérez-Aguila y de Antonio Lledó Cano. Formaban éstos parte del Comité Provincial y la carta, que parecía haber arrancado de unas críticas de Oarrichena a los dirigentes provinciales, estaba redactada en los siguientes términos:

Nuestro querido amigo:

Creiamos tener ocasión de hablar con Vd. antes de su regreso a Madrid el pasado lunes, ya que no pudimos hacerlo el domingo, por nuestro viaje de propaganda a diversos pueblos de la Marina. No habiendo podido hacerlo le dirigimos esta carta porque queremos que lleguen a conocimiento de $\mathrm{Vd}$. las manifestaciones de la misma lo antes posible, sin que tengan la espera de poder aguardar a su regreso.

17 Ibidem, págs. 105 y 114.

18 Chapaprieta, Joaquín, op. cit., pág. 157.

19 Op. cit., pág. 151.

20 29-9-1931. AHN-GC, Madrid, C 569, L 4768. 
Entre nosotros no puede existir resquemor alguno ni motivo de discordia. Las discrepancias o las opiniones diversas deben manifestarse con la sinceridad y franqueza con que hasta ahora se hizo. Cada uno de nosotros cuando tuvo algo que decir a Vd. o de Vd. lo hizo directa y personalmente. Hemos creido siempre que éste es el medio viable entre buenos amigos, y como sabemos que también ha sido ésta la conducta que siempre siguió Vd., nos produce verdadero dolor tener noticias de otra cosa. No se ha enfriado de tal modo nuestra amistad que pueda huirse para decir lealmente lo que uno a otro tengamos que decirnos. Otra cosa es sembrar alarmas donde no existe motivo ninguno para ellas. Nosotros nos sentimos tan íntima y fraternalmente unidos a Vd. como siempre, y si por su parte Vd. también es así no había necesidad alguna de que en la fraternidad radical se' haya alzado la más leve sombra y pueda nadie extraño a nosotros tres pensar que hay motivos graves de discrepancia.

Si Madrid estuviese más cerca, en lugar de dirigir a Vd. esta carta nos habríamos ido nosotros para darle un abrazo al mismo tiempo que le dijéramos todo lo que por escrito no puede decirse, por duro que fuera. Nosotros no intentamos crear un personalismo frente a otro. Tampoco estamos aquí por una satisfacción personal, por vanidad o egoismo. Venimos demostrando un espíritu de sacrificio que si alguien lo iguala no concedemos que lo supere. La Junta Provincial viene actuando como a ella se le alcanza que más satisface los anhelos democráticos de los afiliados, en todo lugar hemos puesto siempre lo más alto que hemos podido el nombre del Partido, de Lerroux y de nuestros representantes en Cortes. Cuando más de cuatro veces alguien lamenta la ausencia reiterada de la provincia, o de ciertos lugares de ella de los Diputados del Partido, siempre tuvimos una justificación cariñosa a su ausencia, y un elggio para su laboriosidad. Esto no puede interpretarse de modo torcido, por muy mala intención que en la interpretación se ponga. Si alguien se considera incompatible con nosotros, nosotros dejamos el puesto a quien merezca la confianza de la Asamblea provincial. Lo que no podemos es dar lugar, ni consentir con nuestro silencio es a que haya motivos de desavenencias o disgusto entre los radicales de la provincia. Lo que Vd. haya de decirnos a nosotros escríbanos a vuelta de correo y dígalo sin rodeos. Nuestra actuación estará siempre guardada por la más noble de las intenciones y el más sano de los propósitos.

Usted conocía mejor que nosotros la organización que en la provincia existía al advenimiento de la República; y conoce también cuanto hasta ahora se lleva hecho. Diga si puede tomarse como correspondencia al esfuerzo la censura a nuestra espalda de la labor que se ha hecho. No es posible que mientras el Partido se acrecienta y la labor se perfecciona nos pongamos nosotros a censurarnos unos a otros o a criticar, por la espalda, lo que los demás hacen. Hemos sido nosotros los primeros que hemos hecho ver la necesidad de que los Diputados se pongan en contacto con los pueblos. Fuimos los primeros que indicamos la conveniencia de enviar una circular suscrita por Vds. tres, ofreciéndose a todos los Ayuntamientos y Comités de la provincia. Aqui no hay personalismo de nadie, y es lamentable que hayan podido hacer mella en $\mathrm{Vd}$. sugestiones de personas extrañas al Partido, celosas sin duda del incremento que quisiera dar a éste la Junta Provincial. 
Nosotros hemos querido llevar a Vd. a todos los pueblos que visitamos; sabe Vd. que nuestra mayor alegría habría de ser llevarle con nosotros en las visitas y en la propaganda en lugar de tener que excusarle por su ausencia; se le ha invitado a Vd. a que asistiera, sin que a su juicio se lo haya permitido la necesidad de estar en Alicante los domingos por lo menos, para hacer actos de presencia en la capital. Y sabiendo todo esto no nos explicamos qué microbio pueda haber dado lugar a unas manifestaciones recientes de $\mathrm{Vd}$. que parecian ponerle frente a la Junta Provincial, y más personalmente frente a nosotros. Aquí no hay nadie frente a otro. ¿Desde cuándo ese antagonismo? Nadie hubiera podido pensar que está bamos en oposición unos con otros. Se pensaría ahora que a nosotros se nos subió a la cabeza el cargo en la Junta Provincial o a Vd. el acta de Diputado. Esta situación de violencia, que a nosotros nos contraría extraordinariamente, no puede prolongarse. Nosotros deseamos una respuesta de $\mathrm{Vd}$. sincera y amistosa. No deje Vd. de,decir lo que diria a un extraño, por fuerte y desagradable que ello sea. En nuestra relación ha de estar en primer término la franqueza.

Y si alguien extraño a nosotros se encarga de interponer incompatibilidades que no existen, diga $V d$. a quien sea que aquí no nos dedicamos a la persecución personal de nadie, que nuestro único deseo es organizar por completo la provincia, con miras sólo al engrandecimiento del Partido. Ni Don Miguel de Cámara ni nadie puede, queriendo de verdad a nuestro Partido, censurar la actuación de la Junta. Donde había una organización radical la hemos respetado, donde existía un radical antiguo y de prestigio, está en primer lugar, y si alguien nos hizo indicaciones que para nosotros fueron órdenes cordiales, fue exclusivamente $\mathrm{Vd}$. $Y \mathrm{Vd}$. que sabe todo ésto no puede tolerar que se ponga nuestra actuación en entredicho. O hemos perdido todos el juicio o se exageran las referencias que llegan hasta nosotros.

Por todo ésto, nosotros deseariamos verle y no pudiendo ser inmediatamente, le escribimos deseosos de recibir su respuesta.

Esperamos que por encima de todos los personalismos agenos y de todas las sugerencias extrañas sepa Vd. poner, una vez más, el verdadero cariño que nos une.

Le envian un fuerte abrazo sus buenos amigos.

Sabemos bien hoy día que estas tensiones tuvieron su origen en la riada de nuevos afiliados, muchos de ellos de pasado monárquico aún sin enfriar, que afluyeron al Partido Radical desde los primeros meses de la República, en la medida en que dicho partido se perfilaba como el mejor albergue de los intereses conservadores dentro del nuevo régimen ${ }^{21}$. La situación

21 Ruiz Manjón-Cabeza, Octavio; El Partido Republicano Radical. 1908-1936, Madrid, 1976, págs. 253-260. 
creó dificultades, a veces insuperables, en las organizaciones locales y puso al descubierto la fragilidad de los intentos de encuadramiento de los partidos republicanos.

El abogado alicantino Rafael Blasco Garcia, que más tarde pasaría a ser presidente de la junta municipal alicantina, escribió el 30 de agosto de 1932 una carta a Lerroux ${ }^{22}$, en la que puso la indicación de "confidencial", y en la que hacía un prolijo análisis de la situación del partido en la provincia. El lector disculpará si, por el innegable interés del documento, lo transcribo en su integridad:

Mi admirado Jefe y querido amigo: Hace mucho tiempo que pensaba escribir a V. para darle noticias confidenciales de cuanto ocurre en nuestro partido, en la provincia y en la Capital, y de la amargura que esto me ocasiona y mueve a no actuar nada políticamente, si no es en la inspiración del periódico nuestro, "Diario de Alicante»; pero el temor de proporcionar a V. un disgusto y el de que algunos correligionarios se sintieran molestos por mi denuncia, me ha obligado a dilatar un dia y otro día este paso difícil que hoy debo de dar para que esté $V$. al corriente de todo y busque la manera de unirnos lo suficientemente prietos para que así permanezcamos eternamente en bien de la República y del Partido por V. creado.

En nuestro Partido no hay homogeneidad: no hay compenetración. Ante la perspectiva del mando cada Comité es un cantón y cada radical un pequeño Lerroux. Todos obramos por nuestra cuenta, no hay norma de conducta fija: las resoluciones son puramente individuales, no se consulta con nadie; lo mismo se organiza un mitin por un correligionario cualquiera que se desatiende una orden de la Junta provincial. En nuestro Ayuntamiento no hay Jefe de minoria; cada cual habla cuando quiere, y como quiere y de lo que quiere. Aquí no buscamos otra cosa que ser lo más pronto amigos del Gobernador: cada cual va a pedir a éste lo que apetecen los que Ilamamos "nuestros amigos"; y los organismos directivos no sabe lo que piden los pueblos, lo que se ha pedido para ellos, ni quien lo pide, porque con nadie se cuenta.

Días pasados me han dicho que el Gobernador recibió de un radical una lista de los funcionarios públicos que se juzgan indeseables en esta Capital. La Junta Municipal y Provincial no sabe nada. Este paso es muy delicado para que se dé por un sólo sujeto, ya que la medida enérgica tiene que producir grandes trastornos familiares y es necesario que, para dar nombres, se haga antes un examen de conciencia y se den por quien tenga un temperamento muy sereno y un sentido moral muy sutilizado.

Otra prueba del desconcierto existente la tiene $V$. en la conducta que observan con "Diario de Alicante". Este periódico nuestro tiene unos novecientos suscriptores: en la provincia hay más de 30.000 afiliados a nuestro

22 AHN-GC, Madrid, C 1720, L 672. 
Partido. Elementos como Pedro Beltrán, Teniente de Alcalde, rico, abogado en ejercicio, no es ni abonado al periódico. Tenemos en éste un déficit mensual de unas cuatrocientas pesetas; hicimos una suscripción mensual extraordinaria y sólo fué aceptada por los cuatro que somos accionistas del periódico; hemos llegado a tener una deuda de catorce mil pesetas que afianzamos D. Nicolas Lloret y yo; pretendimos hacer una derrama entre los Comités provinciales; se aceptó en la última Asamblea del Partido (en Júlio), ponemos en circulación las letras correspondientes a las cuotas asignadas y, en esta fecha, se nos han devuelto todas. Los Gobernadores que tenemos actualmente; los Diputados de la provincia, que son de nuestro Partido, no nos dan más apoyo que la suscripción mensual del periódico. Ha sido inútil el girar letras de sumas módicas; el dirijirles cartas y hablarles pidiéndoles protección.

A nada han respondido. $Y$ aquí, tiene $V$. a cuatro desdichados románticos, que tienen su límite de aspiración en ser Concejales lerrouxistas, sosteniendo una situación incomprensible por la conducta de sus correligionarios y expuestos a ser obligados a pagar un día u otro una porción de miles de pesetas sin tener siquiera el agradecimiento de aquellos a quienes encumbramos y llevamos a puestos elevados.

Claro que esto ocurre por no haber aquí una cabeza destacada a la que subordinarse, pues, en tal caso, se impondría la autoridad, e imperaría la disciplina, pero esta falta debe llenarse o suplirse con una labor colectiva: con una actividad de los Diputados de la provincia que, juntamente, y no con actos públicos, sino particulares, amistosos, de confraternidad, se desenvolvieran visitando los pueblos de la provincia, aconsejando la unión, limando todas las asperezas, juntando a los desunidos y haciendoles ver la necesidad de todo sacrificio por la República y por V., recomendando subordinaciones y protección al órgano del Partido "Diario de Alicante".

Esta visita podia llevar como heraldo una carta de $V$. dirijida a la Junta provincial, a la que "Diario de Alicante" daría publicidad y después imprimiríamos y se repartiría por toda la provincia.

Los términos de esa carta no soy yo quien para indicarlos a $\mathrm{V}$. pero, enterado por mí de nuestro estado de organización y de la conducta de nuestros correligionarios, ya tiene $\mathrm{V}$. conocimiento de lo que ocurre para que $V$. lo glose con su prodigioso talento y su fácil escritura.

Lo único que si me permito decirle (y pido perdón por ello), es que convendría anunciase $V$. en esa carta el viaje por la provincia de los tres Diputados, para que el Partido no tomase la visita como algo personal o protocolario.

No estaría de más, mi querido $\mathrm{D}$. Alejandro, el que recomendase $\mathrm{V}$. a Cámara, Puig y Oarrichena que se preocupasen algo de nuestro periódico y dieran ejemplo con su sacrificio a todos los correligionarios que nos des. atienden y olvidan.

Y finalmente: como llevo treinta áños de sufrir los comadreos y quisicosas de la política provinciana; como yo no aspiro a nada, le adelanto a $V$. que, en cuanto salve la angustiosa situación del periódico o asista a su se- 
pelio, estoy resuelto a retirarme de la política activa. Claro es que no dejaré de ser republicano, ni lerrouxista mientras viva ni, con mi apoyo personal y económico, abandonaré jamás a mi Partido, pero necesito un descanso más espiritual que material en mi vida al comenzar la edad de viejo, particularmente para concretar mis últimos esfuerzos en el bufete cuya explotación necesito para vivir y encauzar a mis hijos para un futuro provechoso, para ellos, y para la patria, si resultaran útiles para ello.

Esto es cuanto creía obligado decir a V. a fuer de buen republicano y mejor amigo de V. Hoy ya quedo tranquilo al advertir a mi Jefe lo que ocurre en Alicante y su provincia; era para mí una obsesión que el Partido se desmembrase, se indisciplinase y $\mathrm{V}$. fuera ignorante de ello: creía un deber de lealtad el advertirlo y lo he advertido; júzgueme V. como quiera; esto no es delación, es simple denuncia de quien está obligado para con una confesión en donde no obran todos como deben y ponen en peligro, si no las ideas, ni las doctrinas, sí la aplicación y el desarrollo de éstas.

Pidiendole perdón por la extensión de esta carta y confiando será leida con la recta intención con que está escrita, le reitera su incondicional adhesión su buen amigo y mejor servidor.

$$
\text { q. e. s. m. }
$$

La carta era la acostumbrada voz del viejo correligionario que se oía en tantas otras provincias españolas y, aunque no quepa perder de vista el indudable apasionamiento de sus apreciaciones, proporciona un filón de datos y una riquísima perspectiva de las dificultades de una organización de un gran partido republicano, en el que no se habían debilitado las expectativas de gobierno, en el marco de la vida provinciana.

Esto no quiere decir que no se reiterasen los intentos de mejorar dicha organización. La asamblea celebrada el 20 de noviembre de 1932 en Alicante aprobó unas Bases de Organización Provincial que se editaron en la imprenta del semanario republicano "El Radical» y, tal vez en cumplimiento de esas bases, el 23 de julio de 1933 se eligió una Junta Municipal en la que aparecía como presidente el citado Rafael Blasco.

También puede relacionarse con estos intentos de reorganización la masa documental, a la que ya se ha hecho referencia, y que contiene datos muy ricos sobre los afiliados del radicalismo alicantino en octubre de 1933. Se trata de boletines de afiliación en los que, junto al nombre completo, aparecían los datos de edad, estado civil, profesión, domicilio y cuota que se abona. Entre esos documentos hay más de seis mil fichas referentes a toda la provincia y relaciones referentes a Elche (392 afiliados), 
Elda (64), Torrevieja (100), Polop (4), Sella (2), Cañada (10), Villajoyosa (7) y Villena (70 afiliados). Aunque estas referencias no puedan ser consideradas, evidentemente, como una información completa del estado de afiliación en la provincia, résulta casi innecesario insistir en el interés de los datos contenidos en esos boletines y relaciones ${ }^{23}$.

\section{EL RADICALISMO EN EL GOBIERNO}

Las elecciones de 1933, sin embargo, iban a actuar de nuevo como elemento distorsionador en la marcha del partido. Los políticos radicales orientaron sus alianzas hacia elementos republicanos conservadores y hacia los sectores del radical-socialismo seguidores de Gordón Ordás y Botella Asensi. El proceso de confección de candidaturas, en cualquier caso, no estuvo exento de incidentes y uno de los radicales que intentaban meterse en la candidatura publicó el 21 de octubre la siguiente hoja de propaganda ${ }^{24}$ :

A los Señores Delegados de los Comités de la Provincia del Partido Republicano Radical

El Sábado 14 apareció en el "Diario de Alicante» una.Convocatoria de Asamblea Municipal para el Domingo 15 con el fin de elegir Candidatos a Diputados a Cortes para la ante-votación del Domingo 22. Esta fué votada por unos 140 afiliados de los 717 que se compone el Censo, no habiendo sido convocados los restantes a esta ante-votación; a propuesta de la Junta Municipal salieron elegidos los señores D. Miguel Cámara y Cendoya; D. César Oarrichena Jenaro y D. José María Ruiz P. Aguila. Seguidamente por Radio Alicante, por la Prensa de Madrid y "Diario de Alicante" se dió la noticia de que habian sido proclamados estos señores en ASAMBLEA (sin indicar era sólo la Municipal de Alicante). Acto continuo los candidatos y sus propagandistas salieron por los pueblos indicando a los Comités eran los elegidos. Como consecuencia, varias Juntas Municipales de Ia Provincia se reunieron y aprobaron la candidatura.

Como hasta el 19 era el plazo prefijado para la presentación de candidatos a la ante-votación del 22 , en ese día quedaron admitidos y fueron proclamados los señores 
D. Miguel de Cámara y Cendoya

D. José Ruiz Pérez Aguila

D. Restituto Mogrovejo Fernández

D. César Puig Martínez

D. César Oarrichena Jenaro

D. Javier Morata Beleño

Al visitar algunos pueblos el firmante para ofrecerse a las Juntas Municipales del Partido, y recabar voluntariamente sus votos, me indicaron que ya el 16 y 17 se habia hecho la proclamación con arreglo a lo acordado por el Partido en Alicante y que ignoraban si habia más candidatos.

El periódico "Diario de Alicante" del día 20 y 21, como ORGANO.DEL PARTIDO RADICAL, no ha publicado la proclamación por la Provincia de los Candidatos anteriormente citados, lo que pongo en conocimiento de los Sres. DELEGADOS.

Los Sres. DELEGADOS, sin presión y libremente, pueden confeccionar sus candidaturas eligiendo el número de ellos que acuerde la Asamblea Provincial del 22 entre los que se indican proclamados el 19 por la Junta Provincial.

Restituto Mogrovejo Fernández

Candidato a Diputado por el Partido Radical

El manifiesto no sirvió de mucho porque, finalmente, serian esos tres nombres los que se incluirian en la candidatura, en unión con un radical socialista de Gordón Ordás y tres de la Izquierda Radical Socialista de Botella Asensi. Alejandro Lerroux, que había sido inicialmente incluido entre los candidatos radicales, renunció a su puesto para dejar paso a Pedro Rico López, que procedia de la Acción Republicana ${ }^{25}$.

La presentación de esta candidatura, exclusivamente republicana, pretendía acotar un terreno político netamente caracterizado entre los que ocupaban, de una parte, los socialistas y sus aliados y, de otra, los partidarios del desaparecido régimen monárquico ${ }^{26}$. Más adelante no dudarian en identificarse abiertamente con las clases medias y con el grupo de los comerciantes y de los pequeños propietarios agrícolas ${ }^{27}$.

25 Garcia Andreu, Mariano, La Segunda República en la ciudad de Alicante: las elecciones, Memoria de licenciatura mecanografiada, Facultad de Filosofía y Letras, Universidad de Alicante, 1982-1983, págs. 165-166.

26 Diario de Alicante, 27 de octubre de 1933.

27 Ibidem, 12 de noviembre de 1933. 
La necesidad de acudir a una segunda vuelta, que se celebró el domingo 3 de diciembre, obligó a acentuar aún más ese sentido conservador, pues Oarrichena, Cámara y Ruiz PérezAguila entraron en coalición con tres de la CEDA, un conservador y Chapaprieta, que figuraba como independiente ${ }^{28}$. Esta seria la candidatura que, finalmente, habría de quedar vencedora.

Las alianzas electorales no hicieron sino prefigurar la trayectoria del radicalismo en los meses siguientes, en los que fue acentuando su política conservadora.

\section{EL COMIENZO DE LA DESCOMPOSICION}

Uno de los más sonados efectos de ese deslizamiento fue la ruptura de Martínez Barrio con el Partido, tras un paso intermedio en el que, para marcar distancias, había abandonado en marzo de 1934 la cartera de Gobernación en el ministerio presidido por Lerroux. La escisión se consumaría a mediados de mayo, pero se veía tan inevitable que, dias antes de que se consumara, el presidente de la Junta Provincial del Partido de Alicante, Rafael Blasco, escribía a Martínez. Barrio una carta ${ }^{29}$ que, a la vez que brinda un excelente testimonio de clima político que determinaba la ruptura, constituye otro documento interesantísimo de lo que era el radicalismo alicantino de aquellos momentos. La abreviatura $h$. es una alusión a la común pertenencia a la masonería.

Alicante, 7 Mayo 1934

Excmo. Sr. D. Diego Martínez Barrio. Madrid

Mi querido y admirado amigo: Perdone $V$. que le moleste pero me creo indispensable hacerlo antes de tomar una resolución definitiva políticamente; creyéndome autorizado para ello, mas que por mi condición de correligionario, como h. suyo.

Las luchas personales entre los Sres. Oarrichena y Ruiz Aguila me han cogido entrambos, ostentando el cargo de Presidente de la Junta Provincial del Partido.

29 AHN-GC, Madrid, C 569, L 4768. 
Como al triunfar mi nombre en las elecciones salió derrotado el Sr. Oarrichena, emprendió éste una campaña de rebeldía contra la Junta Provincial y principalmente contra mí como su Presidente, que ha culminado sacando a la luz pública un libelo dedicado a injuriarme y calumniarme personalmente de forma tal que hace pensar cada número que leo, en la pistola y el homicidio. Pero como yo no soy de esa injundia (sic); como mi conJucta se redujo desde el primer momento a evitar indisciplinas y mantener la autoridad del cargo, cosa que Oarrichena, apollado (sic) por Cámara, no han atendido ni respetado, mi papel era tan difícil que me vi obligado a dimitir la Presidencia.

Al producirse mi dimisión, se convocó a una Junta Provincial en donde se ratificó mi nombramiento requiriéndome para que en el acto fuese presente al lugar de la junta donde fuí y en ella se me dió un amplio voto de confianza para reorganizar el Partido e inspirarlo políticamente. Vuelto al cargo, que no deseaba ni deseo, al iniciar mi labor politica cerca del Gobernador, Sr. Chacón, me veo omitido por éste, que descaradamente sólo acata indicaciones del Sr. Oarrichena, el cual comienza a sustituir Ayuntamientos reemplazando los existentes con elementos de las derechas y de la Dictadura principalmente.

En esta situación, teniendo a mi lado 85 representaciones de pueblos de la provincia, con Cámara y Oarrichena enfrente: con el Gobernador divorciado de la Junta Provincial: los amigos desatendidos; a mi injuriandoseme todas las semanas en "El Radical»: y con una perspectiva de política de derechas a la vista ¿qué voy a hacer yo? Pues aún en la hipótisis (sic) de que una Delegación de la Junta Nacional viniera a solucionar este estado de cosas, y me diera la razón, con la obra de derechas iniciada desde el Gobierno civil e inspirada por Oarrichena yo no puedo presidir la Provincial porque no estoy dispuesto a colaborar ni un momento más con aquella: cual me ocurrió en las últimas elecciones. Y como yo veo al partido inclinado a las derechas, y lo mismo Oarrichena que Ruiz Aguila, resulto entre ellos una cosa exótica, un dirijente en precario que, no teniendo la autoridad necesaria, no puede llevar al partido hacia los derroteros que marca y señala nuestro programa.

En vista de todo ello, tengo el firme propósito de eliminarme de la política. Aqui no puedo actuar en izquierdas por razón de las personas que están al frente de esta organización. Con los radicales no puedo ser izquierda porque ni lo son, ni me dejan los dirigentes que yo lleve al partido a las izquierdas; creo, por tanto, que no hay más remedio que abandonar la políti$\mathrm{ca}$; sobre todo cuando de lo dicho tiene noticia D. Alejandro y la Junta Nacional, y de cuanto se hace por buscar la concordia, e inspirarnos especificamente en los momentos actuales para dirijir el Partido en la Provincia.

Todo esto ocurre y me ocurre. He querido contarlo a $V$. por si cree que debo adoptar otra postura distinta a la que tengo preparada. Sólo V. puede hacerme desistir de mis propósitos con sus sanos consejos o mandatos políticos de orientación que no veo, pues sólo vislumbro derechismo por todas partes. Le ruego me aleccione en estos momentos, si cree $\mathrm{V}$. oportuno el aislamiento que deseo, me relegaré a mi casa de donde no volveré a salir hasta que $V$. me necesite: teniendo presente que, en ella y al salir de ella, será siempre como republicano de izquierdas, que sigue las doctrinas de D. Diego Martínez Barrios. 
Rogándole me dé el alimento espiritual que necesito en estos momentos para resolverme politicamente, le saluda con todo respeto y reitera su afecto y admiración de amigo y $\mathrm{h}$.

Firmado R. Blasco

La crisis se solventó, en el marco alicantino, con la salida de Blasco de la Junta Provincial que, el 28 de julio, dirigía una circular ${ }^{30}$ a los presidente de las juntas municipales $y$, después de aludir a "la pequeña escisión habida en el Partido Republicano Radical", les pedían que reuniesen al partido y acordasen ureiterar la adhesión a D. Alejandro Lerroux y al Partido Republicano Radical". La circular iba firmada por Luis Esteve, vicepresidente, y César Oarrichena, secretario general de la Junta Provincial.

Dos días después de esta invitación a la espontaneidad, los mismos firmantes enviaban otra circular ${ }^{31}$ en la que convocaban, para el 14 de julio, una asamblea provincial en la que se elegirian los cargos vacantes.

El Diario de Alicante, mientras tanto, parece que quedó en poder de los disidentes. A finales de junio informaba de una reunión del Comité Ejecutivo Nacional del Partido Radical ${ }^{32}$ y ponía en boca de Ruiz Pérez-Aguila palabras en defensa de la gestión de Blasco, en las que aludía a la hostilidad encubierta que, contra Blasco y el comité, habían «venido siguiendo significados elementos del partido". Ruiz Pérez-Aguila, sin embargo, no representaba al sector escisionista, sino que, por el contrario, parece que poco después entró en la órbita política de Chapaprieta $^{33}$.

30 AHN-GC, Madrid, C 570, L 4769.

31 lbidem.

32 Diario de Alicante, 30 de junio de 1934.

33 Chapaprieta, Joaquín, op. cit., pág. 386. 
La Asamblea Provincial convocada para el 14 de julio eligió un nuevo Comité Ejecutivo Provincial que quedó constituido de la siguiente forma:

$\begin{array}{llll}\text { Presidente } & \text { César Oarrichena Genaro } & \text { Diputado a Cortes } & \text { Alicante } \\ \text { Vicepresidente } & \mathbf{3 4} & \text { Médico } & \text { Alicante } \\ & \text { Arturo Gadea Pro } & \text { Abogado } & \text { Alicante } \\ \text { Carlos Fernández Boronat } & \text { Médico } & \text { Alcoy } \\ \text { Secretario G. } & \text { Vicente Martínez-Pinna } & \text { Catedrático } & \text { Alicante } \\ \text { Vicesecretarios } & \text { Fernando Navarro Abad } & \text { Industrial } & \text { Novelda } \\ & \text { José Mazón Torrecilla } & \text { Abogado } & \text { Orihuela } \\ \text { Tesorero } & \text { Eduardo Ballester Pavia } & \text { Propietario } & \text { Sagra } \\ \text { Contador } & \text { Vicente Mayor Climent } & \text { Contratista } & \text { Alicante } \\ \text { Vocales } & & \text { Farmacéutico } & - \text { - - } \\ & \text { Joaquín Santo Garcia } & \text { Médico } & \text { Elche } \\ & \text { Francisco Beltrán Olcina } & \text { Abogado } & \text { Elda } \\ & \text { Agustín Montón Ordines } & \text { Farmacéutico } & \text { Denia } \\ & \text { José Botella Berenguer } & \text { Industrial } & \text { Aspe } \\ & \text { Tomás Antón Bayle } & \text { Propietario } & \text { Santa Pola }\end{array}$

La actividad de los nuevos dirigentes radicales se dirigió durante los meses inmediatos al restablecimiento de los orga-

34 Los datos que faltan aparecen concienzudamente tachados en la circular de 16 de julio de 1934, en la que el nuevo presidente anunciaba la composición del nuevo comité. AHN-GC, Madrid, C 570, L 4769. El Diario de Alicante de aquellos días no informa de los nombres de los componentes de ese comité, aunque, en su número del día 17 de julio, publicaba una nota muy crítica sobre el desarrollo de la asamblea:

"Hace unos días hicimos notar nuestra extrañeza ante el hecho de que se anunciara para el pasado domingo la elección de cargos del Comité Provincial del Partido Radical.

"Dijimos que esa elección debería suspenderse por respeto a las autoridades y organismos del Partido. Y pudimos decir más.

"Pudimos decir, porque es verdad, que el señor Lerroux habia ordenado, desde el jueves último la suspensión de ese acto, y pudimos pensar en que dignamente no podia el mismo tener lugar.

"Sin embargo, se ha verificado. Se realizó una elección con menguada concurrencia, acudiendo cortisimo número de representación locales, ya que todas las demás se hallan de acuerdo en censurar y lamentar los métodos y procedimientos que se vienen desarrollando.

"Que conste, pues, que esa asamblea o reunión estaba desautorizada por el Jefe del Partido; que a pesar de ello se ha celebrado y que quienes deban cargos a semejante patraña pueden tener la seguridad de que ni representan a nadie ni podrán ostentar esa representación pintoresca en ninguna parte."

Agradezco esta información al personal de la biblioteca Gabriel Miró, de Alicante. 
nismos afectados por la escisión producida. Buena prueba de ello fue el cruce de cartas entre los diputados Oarrichena y Cámara en relación con el nombramiento de jueces y fiscales municipales y algunos expedientes municipales. En ellas se aprecian las fuertes presiones que, para confirmar su influencia política, los radicales ejercian desde la Dirección de Administración Local y desde el Ministerio de Justicia, ejercido por el radical castellonense Vicente Cantos Figuerola.

Miguel Cámara, que se encontraba en Madrid como diputado, escribía el 27 de julio de 1934 una carta ${ }^{35}$ al también diputado y presidente del Comité Provincial alicantino, César Oarrichena, en la que se ilustraban perfectamente todos estos aspectos:

Querido César: Me tienes incomunicado; no me dices nada de lo que por ahí pasa. Sé lo de Ruiz por la prensa, pero aun ésta no coincide en sus apreciaciones. ¿Has hablado con Chapaprieta? ¿Te has puesto de acuerdo con él para los jueces? $Y$ ya que de esto te hablo, he de decirte que no he recibido, ni por tu conducto ni directamente, ninguna propuesta más de Jueces y Fiscales y sí únicamente una carta del alcalde de Pinoso en la cual me propone el cambio de D. Gregorio Molina Pérez para sustituirlo por D. Francisco Jordán Mendero y me dice que a ti también te ha escrito. ¿Qué hacemos?

El amigo Cantos me pidió le enviara 3 juegos más de la propuesta que le entregamos personalmente y así lo hice; además, le he escrito una carta a Salvador Martínez Moya, en Murcia, enviándole otra relación de nuestros candidatos por haberme enterado de que uno de los magistrados de la Audiencia de Valencia fué pasante de su padre y le une a él una gran amistad. ¿Piensas ir a Valencia como quedaste con el Gobernador? Sería conveniente.

¿El expediente de Denia lo ha pasado ya el fiscal al Juzgado? No olvides ésto porque la fecha se acerca y sería entonces un verdadero fracaso y lo mismo te digo de Onil que son los dos que me apremian en este sentido. Tómalo con interés.

¿Fue ya la inspección a Benitachell y Teulada?

Gobernación tiene orden de Samper de paralizar todos los expedientes de Ayuntamientos, y de Alicante no tenemos en la Dirección de Admón. Local más que un expediente, el de Parcent, que está pendiente de firma, según me dijo el Director.

Dile al Gobernador que te enseñe la Circular de fecha 16 de julio que habrá recibido sobre esta materia.

35 AHN-GC, Madrid, C 569, L 4768. 
D. Alejandro me ha enviado todo el expediente de Benisa que el Comité radical le mandó, para que le conteste urgentemente y ayer mismo le hablé a Salazar y al Director de Admón. Local y creo que conseguiremos quitar la situación con la fórmula que tú conoces y convinimos.

No seas tumbón y contéstame y dame algunas noticias.

Deseando pases delicioso fresco en tu casita de campo y con saludos a tu mujer y a los tuyos, te abraza tu buen amigo, Miguel.

P. S. Escrita esta carta, me llama por teléfono Cantos para que fuera a verle. Vengo del Ministerio y me entregó la relación de nombres que pide Chapa para jueces y fiscales, cuya copia te envio donde verás cosas bien curiosas.

Me llamaba además, para que el próximo martes vayas a Valencia con nuestra relación y visites al Presidente de la Audiencia, quien previamente tendrá la indicación telefónica de que te atienda, etc.

No dejes de hacerlo y vamos a ver si le damos para el pelo a Chapa y derecha.

Defiende bien nuestra posición y además ponte al habla con Carrere o Sigfrido pues ellos han hecho cosa parecida para Valencia y Castellón. Miguel.

La contestación de Oarrichena ${ }^{36}$ minimizaba la importancia del trasvase de Ruiz Pérez-Aguila a las filas chapaprietistas y prestaba más atención a las cuestiones de los jueces y los expedientes municipales.

Querido Miguel: Por fin das señales de vida. Ya era hora. Acabo de recibir tu carta fecha 27. Efectivamente hablé con Chapaprieta y me dió cuenta de la visita de Ruiz y demás cofrades, diciéndome que me comunicaba la noticia para que no creyeramos que se trataba de una maniobra de él. La cosa no tiene importancia, se esperaba para tranquilidad del Partido y desprestigio de los evolucionistas.

Lo de los Jueces va muy tirante pues las Derechas aprietan de lo lindo y no sé como quedaremos, yo tengo hechas varias gestiones, pero lo interesante es que el Ministerio apriete de veras pues, si no, estamos perdidos. Mañana pienso ir a Valencia y me entrevistaré con el Presidente pero no confío mucho salga nada práctico de mi visita, por el motivo de que la Territorial está compuesta de Cavernícolas y Derechistas, por cuyo motivo insisto en que todo depende de nuestro amigo $\mathrm{D}$. Vicente Cantos, verdadero eje de la cuestión.

Lo de Benisa me parece bién que se solucione, pues nuestros amigos están desesperanzados, y con razón, y ya es hora de que se les dé una completa satisfacción. 
Los expedientes de Denia y Onil yá están en el Juzgado. La inspección de Benitachell y Teulada se están efectuando, pero precisa que tú vengas por aqui para hablarte de estas cosas y otras muchas muy interesantes para nuestra Provincia y, en particular, para ti y para mi, que es como si dijeramos para el Partido Radical y para nuestro Jefe D. Alejandro Lerroux.

En Gobernación existen actualmente los expedientes Administrativos incoados a los Ayuntamientos de Parcent, Bigastre, Bañeres, Novelda, Benejama, y en este momento no recuerdo si alguno otro más. Es preciso que estos expedientes se devuelvan ordenando la suspensión de Ayuntamientos y enviándoles al Juzgado. Esto sin pérdida de tiempo pues no hay derecho a que nuestros amigos los tengamos en una continua impaciencia.

Eso de vacaciones y de tomar el delicioso fresco de mi casita de la playa es una tomadura de pelo, pues en mi vida he trabajado como en estos dias que los amigos correligionarios de los Pueblos me acosan con sus visitas y, desde las ocho de la mañana hasta las ocho de la noche, me lo paso en Alicante trabajando. Estoy agotado y me precisa tu valiosa colaboración. De manera que hacerse la pascua y venir por aquí.

Mis afectuosos saludos a tu mujer y tú recibe un fuerte abrazo de tu invariable amigo que te quiere.

Los problemas de organización resultaron ya permanentes en los meses que transcurrieron hasta el colapso del partido y, si hemos de dar pleno crédito al testimonio de Chapaprieta ${ }^{37}$, éste rehusó un ofrecimiento de Lerroux, en septiembre de 1934, para que se hiciese cargo de la dirección del Partido Radical en Alicante ya que, como le explicó el caudillo radical, no estaba contento con los dirigentes radicales de aquella provincia.

La revolución de octubre de 1934 supondria, como en tantos otros lugares, un duro golpe para la consolidación del régimen republicano, y de las filas radicales surgirían voces que denunciaban que los acontecimientos estaban sirviendo de pretexto para la consolidación de posiciones de las derechas. Así lo denunciaba Oarrichena en una carta ${ }^{38}$ que escribió por entonces a Miguel de Cámara, en la que reclamaba la intervención del radical Eloy Vaquero, ministro de la Gobernación en aquellos días.

Querido Miguel: Llegué el martes y me encontré con una serie de desaciertos, cometidos por nuestra primera autoridad, yo creo que de buena fé, pero que nos perjudican gravemente a los Radicales.

3811 de octubre de 1934. AHN-GC, Madrid, C 569, L 4768. 
Están detenidos por orden gubernativa infinidad de republicanos. Algunos se lo merecen, otros es un caso de conciencia el consentir que continúen un minuto mas en la cárcel. Entre los detenidos están Pascual Orts, Emilio Costa, Antonio Ramos Espinós, Rafael Alamo, Juan José Cremades y Casimiro Arques, buenos republicanos y personas incapaces de prestarse a ninguna maniobra contra la República. Yo he pedido al Gobernador la libertad de estos amigos y espero conseguir mi pretensión, pero sería muy eficaz que desde Madrid se le llamara haciéndole esta indicación.

El Ayuntamiento y la Diputación aún no han sido renovados y de la lista que hicimos en ésa, no se ha tocado ningún Ayuntamiento. Las Derechas son las dueñas y Sras. en este Gobierno Civil. De manera que tú verás lo que nos conviene hacer. Yo creo que esto no puede durar así ni un minuto más y precisa que nuestro amigo Vaquero tome una determinación rápida para terminar con lo que sucede en Alicante. pañero.

Espero tus noticias y con todo afecto te abraza tu buen amigo y com-

\section{ACTO FINAL}

La documentación relativa al Partido Radical en la que se basan estos apuntes ofrece un vacío cronológico que llega hasta noviembre de 1935. Para entonces, Lerroux había abandonado la presidencia del gobierno y, unos días más tarde -el 18 de octubre-, una nota oficial del gobierno desencadenaba el escándalo del "straperlo", que supuso el comienzo del derrumbamiento del Partido Radical.

El proceso, sin embargo, intentó evitarse con una comisión reorganizadora, presidida por Santiago Alba, que se eligió el 13 de noviembre dentro de la minoría parlamentaria. Fruto de las tareas de reorganización fue la confección de estadísticas que sirvieron para delimitar el verdadero potencial del partido en cada una de las provincias. Una de ella consistía en una relación ${ }^{39}$ de diputados, presidentes de comités provinciales, presidentes de diputaciones y alcaldes radicales, por provincias. Los datos relativos a Alicante eran los siguientes:

39 AHN-GC, Madrid, C 41, L 734. 
Diputados

Presidente Comité Provincial

Presidente Diputación

Alcalde
D. Miguel de Cámara Cendoya

D. César Oarrichena Genaro

D. César Oarrichena Genaro

D. José Pérez Molina

D. Alfonso Martín Santaolalla

La otra serie estadística ${ }^{40}$, más completa, arrojaba también datos sobre la implantación del partido que, aunque llevaban la fecha de noviembre de 1935, permiten abrigar dudas sobre su vigencia. El panorama del radicalismo alicantino, que a continuación se ofrece, debía corresponder, posiblemente, a los momentos de euforia y máxima influencia que se habian vivido desde las elecciones de 1933.

Alcalde Alfonso Martín Santaolalla

Ex alcaldes radicales Ninguno

Concejales radicales Vicente Martínez Pinna

Francisco Zaragoza Onofre

Francisco Climent Pallarés

Ernesto Villa Lozano

José Gómez Sigüenza

Primitivo Baeza Molina

José Bardiza Ibáñez

Julián Baeza Ibars

Juan José Tortosa Giménez

Cándido Sánchez Muñoz

Antonio Baeza Buades

Presidente Diputación José Pérez Molina (radical)

Ex presidentes radicales de la Diputación Gestores radicales

Ninguno

Arturo Gadea Pro

José Botella

Tomás de Antón Baile

Juan Puigcerver Rives

40 AHN-GC, Madrid. C 44, L 751. 
Número total de comités

constituidos Ciento treinta y dos ${ }^{41}$

Número total de afiliados Seis mil setecientos

Presidente
Vicepresidente $1 .^{\circ}$
Vicepresidente $2 .^{\circ}$
Secretario
Vicesecretario $1 .^{\circ}$
Vicesecretario $2 .^{\circ}$
Vocales

Delegado para la Junta Nacional
COMITE PROVINCIAL

(Avda. Méndez Núñez, 21)

César Oarrichena Genaro

Arturo Gadea Pro

Carlos Fernández Boronat

Vicente Martínez Pinna

Fernando Navarro Abad

Eduardo Ballester Pavía

José Botella Berenguer

Tomás Antón Baile

Alfonso Martón Santaolalla Esquerdo José Pérez Molina

\section{César Oarrichena Genaro}

Tan brillante panorama como la anterior estadistica parece sugerir debió descomponerse en un plazo muy breve y, cuando se disolvieron las Cortes, los radicales alicantinos se encontraron en una situación muy difícil para afrontar las nuevas elecciones que se celebrarian en febrero de $1936^{42}$.

Las fuertes tensiones entre izquierdas y derechas se vieron distorsionadas en Alicante por una interferencia gubernamental que, reponiendo y suspendiendo ayuntamientos en función de sus intereses electorales, provocó un incremento inusual de la

41 En otra parte de ese mismo documento se afirmaba que eran ciento treinta y cuatro, que era el número de pueblos de la provincia.

42 La mejor información global al respecto puede encontrarse en TUSELL, J., Las elecciones del Frente Popular, Madrid, 1971, 2 vols. Para el caso alicantino, resulta indispensable retocar la imagen que ahi se ofrece con lo publicado poco después por ChapAPRIETA, J., op. cit., págs. 385-398, y por la tesis doctoral de Azorin Matesanz, Maria Rosa, El Frente Popular en las elecciones de febrero de 1936 a través de la prensa alicantina, Barcelona, 1975. 
violencia. El atentado al diario El Luchador, el dia 5 de febrero, marcó el tono de un clima de violencia que estallaria, tras conocerse el triunfo del Frente Popular, en el asalto a los locales de Derecha Regional Agraria, y a los de los periódicos El Día, Diario de Alicante y Más. También se provocaron incendios en algunas iglesias y en el reformatorio de adultos ${ }^{43}$.

Antes de que el ambiente se enrareciera hasta esos extremos, los radicales habían intentado entrar en la candidatura contrarrevolucionaria de acuerdo con las indicaciones de los órganos nacionales que, sin embargo, habian concedido una gran autonomía a las organizaciones locales ${ }^{44}$. Fruto de esas gestiones fue la $\operatorname{carta}^{45}$ que, el día 20 de enero, dirigió Oarrichena a Santiago Alba, en la que le exponía las dificultades que se producían en Alicante para traducir en el ámbito local las líneas de entendimiento a las que había llegado en Madrid Gil Robles, Alba, Maura y Cid.

Mi querido amigo y correligionario: En esta fecha aún no hemos llegado a celebrar reunión alguna los partidos del bloque para tratar de la com. posición de la Candidatura que ha de luchar en las próximas elecciones.

Los elementos de la CEDA están muy intransigentes y pretenden cinco puestos, asignándonos a los radicales un sólo puesto y esto no es justo pues el Partido Radical tiene 45 mil votos, la Ceda 55 mil y los amigos de Chapaprieta unos 25 mil. Los puestos de mayoría son 8 y nosotros los radicales creemos con sobrada razón y muy justificada, que nos pertenecen tres sitios, pero por no aparecer como intransigentes estariamos dispuestos a aceptar dos lugares.

Si Vd. cree oportuno indicarle algo a Gil Robles, le agradecerá el Partido Radical de Alicante esta gestión y, además, que en esta gestión apoyará Vd. una cosa muy justa.

La contestación de Alba ${ }^{46}$, que se fechaba tres días más tarde, ponía de manifiesto que la autonomía de las organizaciones

44 Ruiz Manjon-Cabeza, El Partido..., pág. 560.

45 AHN-GC, Madrid, C 522, L 477.

46 AHN-GC, Madrid, C 569, L 4768. 
locales era pura y simplemente desobediencia a los organismos nacionales.

Mi querido amigo y Correligionario: Sólo dos líneas, pues estoy tan agobiado de trabajo como puede imaginar por la simple lectura de los periódicos. Repetidamente he conferenciado con el señor Gil Robles, quien me asegura que mantiene el pacto establecido conmigo para que los radicales dispongan de dos nombres en la candidatura de esa provincia. Me afirma que en tal sentido comunica instrucciones a sus correligionarios, con los que deben Uds. hablar inmediatamente.

Las noticias que nos llegan expresan que quien estorba el acuerdo es el señor Chapaprieta o sus amigos. Ustedes me informarán, en consecuencia.

También fue pronta la contrarréplica de Oarrichena ${ }^{47}$. El 26 de enero confirmaba la negativa de los cedistas alicantinos a doblegarse a las inspiraciones de Madrid y anunciaba que las negociaciones entre cedistas y el gobierno habían desembocado en la oferta de los primeros para que el ex radical Miguel de la Cámara Cendoya, que por aquellos días desempeñaba la subsecretaria de la Presidencia, figurase en un puesto de la candidatura de derechas. La situación resultaba humillante para los supervivientes del radicalismo.

Mi querido amigo y correligionario: Tan pronto fué en nuestro poder su carta visitamos al presidente de la organización de la Derecha Regional Agraria (Ceda) y estos señores insisten en que los nombres de la candidatura han de ser 4 de la Ceda, un radical, un monárquico, un chapaprietista y un octavo puesto para Cámara, como representante del Gobierno.

Esto, amigo don Santiago, es inadmisible, pues no es justo que el Partido Radical, con 40 mil votos tenga un puesto y que se le regale un acta a un monárquico y a un representante del Gobierno que no tienen votos en esta provincia.

Como mañana 25 celebran una reunión los representantes de la Ceda en Valencia con el jefe Regional Sr. Lucia y han de decidir en definitiva, convendría que Vd. Ilamara a Gil Robles y, por teléfono, éste comunicara con Valencia insistiendo en que al Partido Radical deben de asignarle dos puestos como mínimo.

El turbio cambalacheo entre derechas y gobierno, que ha descrito Chapaprieta con lujo de detalles, llevó a Portela a un inicial entendimiento con los partidos del Frente Popular, que tuvo como consecuencia inmediata la reposición de los ayuntamien-

47 Ibidem. 
tos que habian sido suspendidos tras la revolución de octubre de 1934. Significaba un evidente fortalecimiento de las posibilidades del Frente Popular y la prensa de aquellos días reflejó declaraciones del nuevo alcalde que sirvieron para atizar los ánimos y preparar las explosiones de violencia que ya han sido aludidas.

El día 16 de febrero, a ser dueños de la calle, a imponerse y a impedir que voten las mujeres, las beatas y las monjas. El 17 no quedará en Alicante una cabeza de derecha sobre los hombros ${ }^{48}$.

La situación, sin embargo, se modificaría, y las derechas terminaron por alcanzar un acuerdo un acuerdo con el Gobierno y confeccionar una nueva candidatura que se hizo pública en la prensa del día 8, a la vez que la del Frente Popular. Colofón previsible de la inversión de alianzas fue el retorno a la suspensión de ayuntamientos, que se sucedieron hasta la víspera de la jornada electoral, contribuyendo a enrarecer aún más el ambiente.

Víctima inmediata de la nueva situación fueron los radicales, que vieron arrojado a su candidato Oarrichena de la candidatura contrarrevolucionaria, aunque no desistiera de presentarse en solitario.

En esas condiciones, los 1.332 votos ${ }^{49}$ cosechados por el que había sido diputado radical en las dos legislaturas anteriores resultaban suficientemente expresivos de la sima en que había caído el partido. Eran, prácticamente, un certificado de defunción.

El radicalismo alicantino no había sido, desde luego, un caso especial, pero los documentos que hemos podido exhumar ilustran ampliamente el fenómeno de desbordamiento que sufrió el Partido Radical. Un partido que no encontró nunca la fór-

Las Provincias, Valencia, 2 de febrero de 1936. No hay que olvidar que se trata del testimonio de un periódico de derechas, pero la misma publicación de la frase es todo un indicio del clima que se vivia.

49 Tusell, J., op. cit., vol. II, pág. 268. 
mula para articularse de acuerdo con las exigencias planteadas por el régimen republicano. Un régimen por el que, paradójicamente, decian haber estado luchando durante más de veinte años. 